УДК 355.40:004.83

Сергій Станіславович Гаценко (кандидат технічних наук)

Костянтин Миколайович Сапожников

Вімалій Миколайович Сташко

Сфім Вікторович Сейфетдінов

Національний університет оброни Украӥни імені Івана Черняховського, Київ, Украӥна

\title{
ПІДХІД ДО ПОБУДОВИ БАГАТОПОЗИЦІЙНОЇ СИСТЕМИ МІСЦЕВИЗНАЧЕННЯ ДЖЕРЕЛ РАДІОВИПРОМІНЮВАННЯ
}

\begin{abstract}
Умови вирішення завдання побудови надійної системи моніторингу вимагає вирішення важливого завдання місиевизначення джерел радіовипромінювань. Серед різноманіття методів визначення координат джерела радіовипромінювання (ДРВ) діапазону коротких хвиль (КХ) найбільш широке застосування знайшов тріангулячійний (кутомірний) метод. Його реалізація вимагає наявності не менше двох приймачів-пеленгаторів, рознесених на відстань, визначену як база пеленгування, з точною взаємною тимчасовою синхронізацією при електромагнітній доступності об'єкта пеленгування одночасно для всіх постів. Постійне виконання цих умов у КХ діапазоні ускладнено з огляду на те, що характеристики поширення радіохвиль істотно залежать від профілю та електрофізичних параметрів радіотрас і схильні до сезонних $і$ добових флуктуацій конщентрачії заряджених частинок у шарах іоносфери. При порушенні умов доступності або відсутності тимчасової синхронізації в системі визначення місцезнаходження єдиним доступним для вимірювання параметром стає направлення на ДРВ з одного пеленгаторного посту, щуо виключає можливість тріангулячійної оцінки координат.

Для усунення зазначеного недоліку у статті проведено аналіз умов іоносферного поширення радіохвиль та виявлено основні фактори, щуо впливають на порушення електромагнітної доступності джерел радіовипромінювання для приймачів-пеленгаторів тріангуляиійної системи визначення місиезнаходження в діапазоні коротких хвиль. Представлений спосіб очінки координат випромінювачів за вимірами амплітуд їх сигналів системою програмно-керованих приймачів, розміщених у зонах електромагнітної доступності. Отримано оцінки зміни областей розташування об'єктів при спільній оцінці амплітуд сигналів у багатопозиційній системі приймачів-вимірювачів та напрямів їх приходу віддаленими пеленгаторами.
\end{abstract}

Ключові слова: пеленгування, тріангулячія, поширення радіохвиль, іоносфера Землі, багатопозиційна система визначення місцезнаходження, ортодромія, азимут.

\section{Вступ}

Постановка проблеми. В даний час 3 безлічі методів визначення координат джерела радіовипромінювання (ДРВ) діапазону коротких хвиль (КХ) найбільш широке застосування знайшов тріангуляційний (кутомірний) метод [1]. Його реалізація вимагає наявності не менше двох приймачів-пеленгаторів, рознесених на відстань, визначену як база пеленгування, 3 точною взаємною тимчасовою синхронізацією при електромагнітній доступності об'єкта пеленгування одночасно для всіх п остів. Постійне виконання цих умов у КХ - діапазоні ускладнено 3 огляду на те, що характеристики поширення радіохвиль істотно залежать від профілю та електрофізичних параметрів радіотрас і схильні до сезонних i добових флуктуацій концентрації заряджених частинок у шарах іоносфери [2]. При порушенні умов доступності або відсутності тимчасової синхронізації в системі визначення місцезнаходження єдиним доступним для вимірювання параметром стає направлення на ДРВ з одного пеленгаторного посту, що виключає можливість тріангуляційної оцінки координат. Для усунення зазначеного недоліку розроблений спосіб оцінки координат ДРВ на основі вимірювання амплітуд сигналів багатопозиційною системою приймачів, розташованих в зоні електромагнітної доступності.

Аналіз останніх досліджень і публікацій.

В роботі [2] запропонована математична модель застосування градієнтних методів локальної оптимізації розміщення засобів багатопозиційної радіопеленгаторної мережі короткохвильового діапазону, для довільних районів (секторів) радіомоніторингу при використанні в якості цільової функції середньоквадратичної похибки визначення координат джерел радіовипромінювання. В роботі [4] визначено, що недостатньо дослідженим залишається питання визначення топології стаціонарної системи радіомоніторингу в короткохвильовому діапазоні. У [5] отримано 
результати, які дозволяють реалізувати квазіоптимальний вибір параметрів структури багатопозиційної радіотехнічної системи за критерієм «ефективність-вартість», але розглянута методика не враховує особливостей застосування пеленгаційного методу визначення координат i реалізована на припущенні щодо можливого розміщення елементів багатопозиційної радіотехнічної системи біля вершин правильного багатокутника. У [6] пропонується вирішення завдання оптимізації структури системи РМ шляхом вибору спочатку оптимальної кількості засобів радіоконтролю і в подальшому врахування ï просторового положення за критерієм «ефективність-вартість». В [3] вирішене завдання розміщення засобів пеленгування багатопозиційної радіопеленгаторної мережі (БРПМ) короткохвильового діапазону шляхом використання градієнтних методів оптимізації. Оптимізація розміщення засобів виходячи 3 аналізу роботи [6] не повністю враховує структуру багатопозиційної радіопеленгаторної мережі для довільної кількості пеленгаторів і реалізована відносно одного ДРВ. Таким чином перспективним напрямком пошуку шляхів підвищення точності визначення координат ДРВ є застосування оптимізаційних процедур побудови БРПМ, що не потребує великих ресурсних затрат i забезпечує підвищення ефективності їх роботи.

Мета статті. Враховуючи специфіку завдань місцевизначення, виникає необхідність у вирішенні завдання оптимізації системи приймачів (ii конфігураціï) за критерієм електромагнітної доступності до ДРВ, i запропонований підхід підвищення точності визначення координат ДРВ системою місцевизначення на основі вимірювання амплітуд сигналів багатопозиційною системою приймачів, розташованих в зоні електромагнітної доступності.

\section{Виклад основного матеріалу дослідження}

Радіозв'язок у КХ - діапазоні просторовою хвилею можливий внаслідок наявності високо іонізованого шару атмосфери Землі - іоносфери. Нижня межа іоносфери розташовується приблизно на висоті 60 км, зі зростанням висоти відбувається іiі розшарування [9]. Освіта іоносфери обумовлено Сонячним випромінюванням, що сприяє появі великої кількості вільних заряджених частинок електронів та іонів. Насправді прийнято розрізняти чотири області іонізації суттєві поширення радіохвиль: D, E, F1, F2. Найнижча область D знаходиться на висотах $60 . .90$ км і існує лише вдень. Область Е розподіляється висотах 90..120 км. Область F1 утворюється лише у світлий час доби у літні місяці і розташовується висотах $120 \ldots 240$ км. Область F2 розташована на висотах $240 \ldots 400$ км. Таким чином, вдень існують усі області, а вночі через рекомбінацію електронів лише шар E та F2. Значення висот вказані орієнтовно, насправді висота шарів, концентрація електронів та інші параметри зазнають значних варіацій, як регулярні так і епізодичні. Регулярні варіації в D та Е області насамперед визначаються рівнем освітленості іоносфери і тому добові та сезонні варіації найбільш значні. В областях іоносфери $\mathrm{D}, \mathrm{E}$ та $\mathrm{F} 1$ добовий хід зміни електронної концентрації постійний i повторюється від доби до доби, тоді як область F2 $\epsilon$ нестійкою і постійно змінюється за висотою та концентрацією електронів. У цій галузі часто відбуваються обурення, що призводять до різких змін іiі параметрів. Добовий хід електронної концентрації шару F2 не має симетрії щодо полудня, як це спостерігається у шарах Е та F1. У річному ході електронної концентрації на середніх широтах є два максимуми, менший у тому числі спостерігається у лютому, а більший - у жовтні. Розподіл електронної концентрації залежить від широти, де вплив на ії розподіл вносить магнітне полі Землі. Крім регулярних шарів, в іоносфері на висоті розташування шару Е періодично утворюються неоднорідності, що являють собою скупчення досить великої площі іонізованого газу 3 підвищеною електронною концентрацією, що переміщуються під дією вітру, що існує в iоносфері. Ці утворення отримали назву епізодичних слоїв $[2,4$,$] .$

Для отримання актуальних даних про стан іоносфери використовують методи прямого вимірювання спеціальними ракетами вертикального, похилого, зворотно-похилого зондування, просвічування іоносфери сигналами із супутників. Однак ці методи не можуть дати повну інформацію в режимі реального часу для всієї поверхні Землі. Тому широке застосування отримали іоносферні моделі, що дозволяють відновити профіль електронної концентрації в областях, де немає даних будь-яких вимірювань. В даний час найбільш розробленою i динамічно розвивається модель IRI [5]. Основними джерелами даних, що використовуються в даній моделі, $\epsilon$ : всесвітня мережа іонозондів, супутникові та ракетні вимірювання, а також дані радарів некогерентного розсіювання. Модель IRI дозволяє обчислювати профілі електронної концентрації (в діапазоні висот від 50 до 2000 км), повне електронне утримання, температуру електронів, іонів і т.д. в залежності від часу та координат. Інша модель NeQuick - іоносферна емпірична модель, де використовуються дані глобальної мережі іонозондів, а також індекси сонячної активності (наприклад, кількість сонячних плям). Модель NeQuick дозволяє отримувати профілі електронної концентрації залежно від часу та географічних координат. Порівняльний аналіз цих та інших моделей представлений у [7].

Таким чином, у процесі поширення коротких хвиль беруть участь усі шари іоносфери. При цьому області D і E є поглинаючими, а область F2 - відбиває. Електронна концентрація області Е $\epsilon$ недостатньою для відображення коротких хвиль, 
тому відображення походить від шару F2 [4,5]. Поєднання іоносферних збурень 3 варіаціями магнітного поля призводить до суттєвих змін характеристик радіоканалу в діапазоні КХ і може призводити до порушення електромагнітної доступності об'єктів для пеленгаторних постів.

Для визначення координат ДРВ [3] запропонований метод, заснований на тому, що амплітуда сигналу зворотно пропорційна квадрату дальності до ДРВ. Отже, для визначення його координат необхідно обчислити відстані до приймальних пунктів i знайти точку перетину ліній положення, відповідних виміряним значенням напруженості. Разом $з$ тим, за рахунок застосування п'яти приймачів, розміщених за стільниковим принципом, при середньоквадратичних помилках виконаних вимірювань 3...5 дБ досяжна точність визначення не перевищує $10 \%$ від радіуса контрольованого району.

В якості вимірювачів амплітуди можна використовувати просторово розподілену систему програмно-керованих приймачів [10], розташованих в електромагнітній доступності до ДРВ. Такі приймачі нині отримали активний розвиток завдяки впровадженню нових технологій у обчислювальну техніку. Програмно-керовані приймачі $\epsilon$ діапазонними пристроями 3 надширокосмуговими антенами, аналогоцифровими перетворювачами (АЦП), програмованими логічними інтегральними схемами (ПЛIC) і каналами передачі даних USB або Ethernet. Ïх програмне забезпечення дозволяє здійснювати розраховане на багато користувачів управління трансіверами i ресиверами за допомогою віддалених комп'ютерів, підключених до глобальної інформаційно-телекомунікаційної мережі.

Особливість архітектури програмно-керованих приймачів полягає у відсутності перетворень сигналів, пов'язаних із перенесенням по частоті, що усуває побічні канали прийому [10]. У приймачі виконується миттєве перетворення аналогового сигналу в цифрову форму. У цьому верхня межа спектра сигналу визначається обчислювальними ресурсами мікросхеми АЦП. 3 використанням сучасних мікросхем АЦП реалізується обробка сигналів із шириною смуги до 1 ГГц.

Високошвидкісні мікросхеми ПЛІС, що використовуються в приймачах, реалізують функції цифрових знижувальних конвертерів. Вони проводять вибірки спектрів сигналів необхідної смуги і передають їх на обчислювальні процесори для обробки. В результаті формуються цифрові потоки меншої інтенсивності. Із загального цифрового потоку можна назвати необхідну кількість потоків, створивши цим одночасно кілька каналів прийому, тобто. реалізувавши кілька «віртуальних приймачів» у діапазоні робочих частот.

Візуальне виявлення сигналу відбувається за результатами аналізу спектра. При розрахунку спектра сигналу, як правило, вибирається 4096 або 8192 точки, залежно від необхідної детальності аналізу та дозволу монітора, що зростають зі збільшенням детальності відтворення структури сигналу. Внаслідок малого відношення числа точок до відліків, що надходять з АЦП (30 ... 60 млн.), для відображення панорами спектра сигналу в мікросхемі ПЛІС виконується розподіл його смуги на блоки, число яких дорівнює необхідному числу пікселів екрану. За максимальним значенням сигналу у блоці формується потік даних для програми відображення спектра [9]. Для оцінки рівня прийому підходить стандартний інструмент зі складу програмного забезпечення програмно-керованого приймача - S-метр. S-метр являє собою вимірювач сили радіосигналу, що приймається, в умовних балах шкали S. На конференції Міжнародного союзу радіоаматорів, були встановлені наступні стандарти калібрування S-метра: зміна сили сигналу на один бал шкали $\mathrm{S}$ відповідає його зміні на 6 дБ; на частотах до 30 МГц за S9 приймається рівень сигналу на вході приймача - 73 дБм (50 мкВ при вхідному опорі приймача 50 Ом). Технічно S-метр є вольтметром 3 логарифмічною шкалою. Очевидно, що рівномірність амплітудно-часової характеристики сигналу свідчить про стабільність іоносферного каналу поширення радіохвиль в даний момент часу.

Похибка оцінки координат пов'язані з безліччю чинників. Найбільш суттєвими з яких є:

завмирання сигналу на трасі розповсюдження, зумовлені багатопроменевістю та перевідображеннями від різних шарів іоносфери;

неоднозначність оцінки напряму прийому радіосигналу;

прийом може здійснюватися 3 бокового або заднього пелюстки діаграми спрямованості антенно-фідерної системи;

спрямовані властивості антени ДРВ.

Похибка може бути зменшена за рахунок усереднення результатів багаторазових вимірювань амплітуд сигналів і вибору приймачів 3 найкращою електромагнітною доступністю випромінювача, що дозволяє досягти високої надійності аналізу динамічних станів радіоелектронних об'єктів при зміні режимів їх роботи, параметрів сигналів і застосуванні заходів маскування

У випадку, коли про ДРВ відома тільки область його ймовірного розташування, отримана амплітудним методом, як помилка місцевизначення та направлення на нього з одного приймально-пеленгаторного посту, пропонується підхід, що базується на спільному вимірі амплітуд сигналів багатопозиційною системою приймачів та напрямів їх приходу пеленгаторним постом.

На рисунку 1 коло радіуса r відповідає помилці місцезнаходження ДРВ отриманої амплітудним методом і $\epsilon$ областю ймовірного розташування ДРВ. 


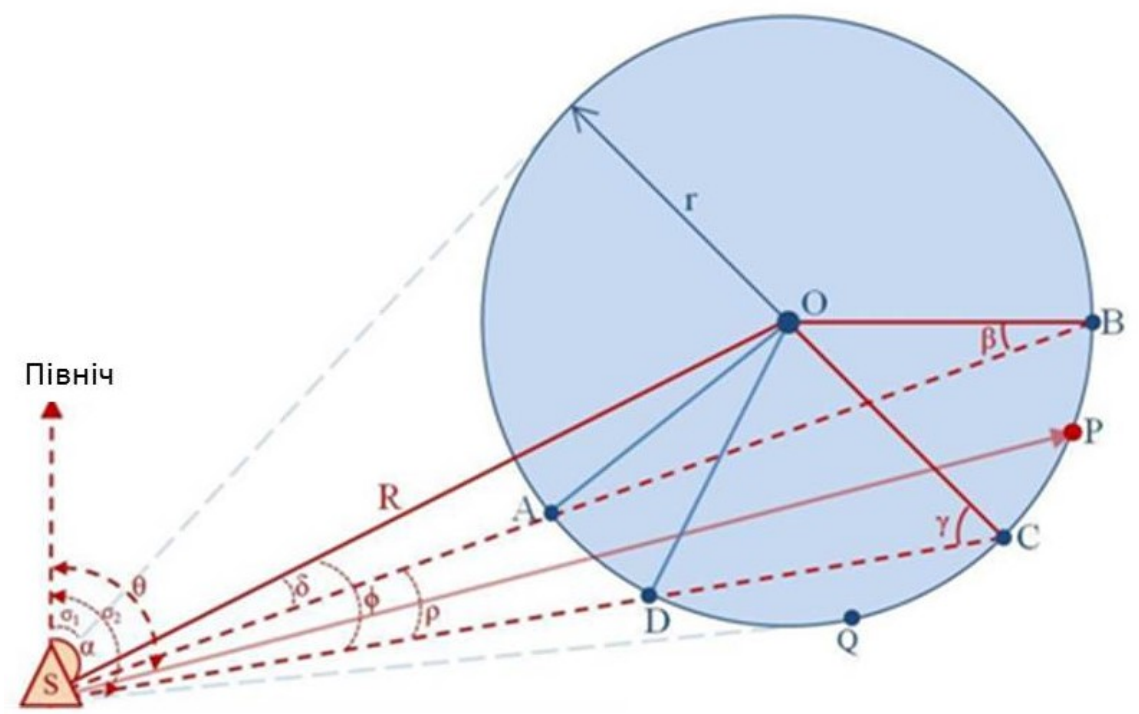

Рис. 1. Сутність підходу визначення ДРВ при спільній оцінці амплітуд та напрямів приходу сигналів.

В основу підходу покладено припущення про те, що при частковому збігу напрямку приходу сигналу $\theta$ до віддаленого пеленгаторного посту 3 областю ймовірного розташування ДРВ область їх перетину $\mathrm{ABCD}$, обумовлена помилкою пеленгування $\rho$, буде істотно менше вихідної області ймовірного розташування ДРВ, розмір якої визначається значеннями $\sigma 1 \sigma 2$.

3 рисунку 1 випливає, що площу $S_{A B C D}$ можна обчислити як різницю площ сегментів $S_{A B Q}$ та $S_{C D Q}$ кола. Відповідно до теореми синусів [10] для трикутників SOB та SOC справедливі співвідношення

$$
\begin{aligned}
& \frac{\mathrm{OB}}{\sin \delta}=\frac{R}{\sin \beta}, \\
& \frac{\mathrm{OC}}{\sin o}=\frac{R}{\sin \gamma} .
\end{aligned}
$$

3 (1) і (2) випливає

$$
\beta=\arcsin \left(\frac{R \sin \delta}{\mathrm{OB}}\right), \gamma=\arcsin \left(\frac{R \sin o}{\mathrm{OC}}\right),
$$

де $\mathrm{OB}=\mathrm{OC}=\mathrm{r}$ - радіус кола, $\mathrm{R}-$ відстань між центром кола $\mathrm{O}$ та пеленгаторним постом, кути $\delta \mathrm{i}$ $\phi$ обчислюються 3 використанням наступних виразів:

$$
\beta=(\theta-\alpha)-\frac{\rho}{2}, o=(\theta-\alpha)+\frac{\rho}{2},
$$

де $\theta$ - пеленг на ДРВ.

Розрахунок азимуту $\alpha$ та відстані $\mathrm{R}$ по ортодромії між двома точками 3 географічними координатами $(\varphi 1, \lambda 1)$ та $(\varphi 2, \lambda 2)$ на земній поверхні здійснюється рішенням зворотного геодезичного завдання на сфері.

3 теореми косинусів [10] випливає, що

$$
\cos \sigma=\sin { }_{1} \sin { }_{2}+\cos { }_{1} \cos { }_{2} \cos \omega,
$$
де $\omega=\lambda_{2}-\lambda_{1}$.

Тоді, $s=a \sigma, \quad$ при негативному $\cos \sigma$ $s=a(\pi-|\sigma|)$, де $a-$ радіус Землі (6378 км). Застосовуючи теорему котангенсів, знайдемо прямий азимут $\alpha$ :

$$
\operatorname{tg} \alpha=\frac{\cos { }_{2} \sin \omega}{\cos { }_{1} \sin { }_{2}-\sin { }_{1} \cos { }_{2} \cos \omega} .
$$

Оскільки сума кутів будь-якого плоского трикутника дорівнює $180^{\circ}$, розрахуємо кути АОВ та DOC

$$
\mathrm{AOB}=180-2 \beta, \mathrm{DOC}=180-2 \gamma .
$$

Таким чином,

$$
\begin{gathered}
S_{\mathrm{ABQ}}=\frac{1}{2}(\mathrm{AOB}-\sin (\mathrm{AOB})) r^{2}, \\
S_{\mathrm{CDQ}}=\frac{1}{2}(\mathrm{DOC}-\sin (\mathrm{DOC})) r^{2} .
\end{gathered}
$$

У виразі 8 кути AOB та DOC обчислюються в радіанах. Обчисливши площі сегментів $A B Q$ i $\mathrm{CDQ}$, отримаємо потрібну площу

$$
S_{\mathrm{ABCD}}=S_{A B Q}-S_{\mathrm{CDQ}} .
$$

Область ймовірного розташування ДРВ, визначена системою вимірювачів сигналів амплітуд, характеризується площею кола $S_{\text {kola }}$ радіуса r. Тому, використовуючи вирази

$$
\begin{gathered}
k=\frac{S_{\text {kola }}}{S_{\mathrm{ABCD}}}, \\
K=100\left(1-\frac{1}{k}\right) .
\end{gathered}
$$

маємо можливість визначити зміну області ймовірного розташування ДРВ при спільній оцінці амплітуди та напрямку приходу сигналу. 


\section{Висновки й перспективи подальших} досліджень

На підставі проведеного аналізу іоносферного поширення радіохвиль виявлено, що в умовах відсутності електромагнітної доступності ДРВ для реалізації кутомірних методів визначення місцезнаходження, вимірювання координат можна проводити шляхом оцінки рівня сигналу. Похибка такого визначення ускладнює просторову

\section{Лimepamypa}

1. Радиотехническая разведка / Ю. А. Смирнов. - М. : Воениздат, 2006. - 456 с. 2. Добрынин И.С. Оптимизация размещения средств радиоконтроля коротковолнового диапазона волн, использующих пеленгационный метод определения координат источников радиоизлучения / И.С. Добрынин, А.Н. Бовкун, В.И. Писаревский // Зб. наук. праць ХВУ. - Х. ХВУ, 2003. - № 3 (46). - С. 67-69. 3. Котенко В.М., Меленський В.Д., Шубін Д.К.. Математична модель застосування градієнтних методів для оптимізації розміщення засобів багатопозиційної радіопеленгаторної мережі короткохвильового діапазону. Вісник ЖДТУ. Серія "Технічні науки", 2014, 1(68), 59-65. (2014). 4. Добрынин И.С. Оптимизация размещения средств радиоконтроля коротковолнового диапазона волн, использующих пеленгационный метод определения координат источников радиоизлучения / И.С. Добрынин, А.Н. Бовкун, В.И. Писаревский // Зб. наук. праць ХВУ. - Х. : ХВУ, 2003. - № 3 (46). - С. $67-$ 69. 5. Ковбасюк С.В. Методика оптимізації структури системи радіомоніторингу короткохвильового діапазону селекцію компактно розташованих ДРВ. Для підвищення точності визначення координат можна використовувати методику спільної оцінки амплітуди та напряму приходу сигналу.

Проведені розрахунки показали, що залежно від ступеня збігу напрямку приходу сигналу до віддаленого посту пеленгатора 3 областю ймовірного розташування ДРВ точність позиціонування ДРВ зростає на $65 \ldots 90$ \%.

хвиль / С.В. Ковбасюк, О.І. Логінов, В.П. Любиченко // 3б. наук. праць ЖВІРЕ. - Житомир : ЖВІРЕ, 2004. 6. Слободянюк П.В. Радиомониторинг: вчера, сегодня, завтра (Теория и практика построения системы радиомониторинга) / П.В. Слободянюк, В.Г. Благодарный ; под общ. ред. П.В. Слободянюка. Прилуки : ООО «Издательство «Аір-Поліграф», 2010. 296 с. 7. Ковбасюк С.В. Методика оптимизации выбора параметров структуры многопозиционного радиолокационного комплекса / С.В. Ковбасюк., А.А. Писарчук // Пробл. упр. и информатики. - 2003. - № 6. C. 120-128. 8. Короткі хвилі: веб-сайт. URL: https://ru.wikipedia.org/wiki/Короткие волны (дата звернення 01.06.2021). 9. Кутомірні радіонавігаційні системи: веб-сайт. URL: https://studfile.net/preview/3642480/ (дата звернення 17.09.2021). 10. Рембовский А.М., Ашихмин А.В., Козьмин В.А. Радиомониторинг: задачи, методы, средства (3 - е издание, под редакцией доктора тех. наук А.М. Рембовского, 640с., 2012 г.)

\title{
ПОДХОД К ПОСТРОЕНИЮ МНОГООПОЗИЦИОННОЙ СИСТЕМЫ МЕСТООПРЕДЕЛЕНИЯ ИСТОЧНИКОВ РАДИОИЗЛУЧЕНИЯ
}

\author{
Сергей Станиславович Гаценко (кандидат технических наук) \\ Константин Николаевич Сапожников \\ Виталий Николаевич Сташко \\ Ефим Викторович Сейфетдинов
}

\section{Национальный университет обороны Украины имени Ивана Черняховского, Киев}

Условия решения задачи построения надежной системы мониторинга требует решения важной задачи местоопределения источников радиоизлучений. Посреди обилия способов определения координат источника радиоизлучения (ДРВ) спектра маленьких волн (КВ) более обширное применение отыскал триангуляционный (угломерный) способ. Его реализаџия требует наличия не менее двух приемниковпеленгаторов, разнесенных на расстояние, определенное в качестве базы пеленгования, с точной взаимной временной синхронизачией при электромагнитной доступности объекта пеленгования одновременно для всех постов. Постоянное выполнение этих условий в КВ диапазоне затруднено ввиду того, что характеристики распространения радиоволн существенно зависят от профиля и электрофизических параметров радиотрасс и склонны $к$ сезонным и суточным фрлуктуациям концентрации заряженных частиц в слоях ионосферы. При нарушении условий доступности или отсутствии временной синхронизации в системе определения местоположения единственным доступным для измерения параметром становится направление на ДРВ с одного пеленгаторного поста, что исключает возможность триангуляционной оценки координат. Для устранения этого недостатка в статье проведен анализ условий ионосферного распространения радиоволн и выявлень основные факторы, влияющие на нарушение электромагнитной доступности источников радиоизлучения для приемников-пеленгаторов триангуляционной системы определения местоположения в диапазоне коротких волн. Представлен способ оченки координат излучателей по измерениям амплитуд их сигналов системой программно управляемых приемников, размещенных в зонах электромагнитной доступности. Получены оценки изменения областей расположения объектов при общей оченке амплитуд сигналов в многопозиционной системе приемников измерителей и направлений их прихода удаленными пеленгаторами.

Modern Information Technologies in the Sphere of Security and Defence № 3(42)/2021 ISSN 2311-7249(Print)/ISSN2410-7336(Online) 
Ключевые слова: пеленгирование, триангуляция, распространение радиоволн, ионосфера Земли, многопозиционная система месторасположения, ортодромия, азимут.

\title{
APPROACH TO BUILDING MULTI-POSITION SYSTEM OF RADIATION SOURCES
}

\author{
Serhii Hatsenko (Candidate of Technical Sciences) \\ Kostiantyn Sapozhnykov \\ Vitalii Stashko \\ Yefim Seifetdinov
}

\section{National Defence University of Ukraine named after Ivan Cherniakhovskyi, Kyiv, Ukraine}

Conditions for solving the problem of building a reliable monitoring system requires solving the important problem of locating sources of radio radiation. Among the variety of methods for determining the coordinates of a radio source (DRV) of the short-wave range (HF), the most widely used triangulation (angular) method. Its implementation requires at least two direction-finding receivers spaced at a distance defined as the direction-finding base, with accurate mutual time synchronization with electromagnetic availability of the direction-finding object simultaneously for all posts. Continuous fulfillment of these conditions in the HF range is complicated by the fact that the characteristics of radio wave propagation significantly depend on the profile and electrophysical parameters of radio paths and are subject to seasonal and diurnal fluctuations in the concentration of charged particles in the ionosphere. In case of violation of the conditions of availability or lack of temporary synchronization in the positioning system, the only parameter available for measurement is the direction to the DRV from one direction finder, which eliminates the possibility of triangulation estimation of coordinates. To eliminate this shortcoming, the article analyzes the conditions of ionospheric propagation of radio waves and identifies the main factors influencing the violation of electromagnetic availability of radio sources for direction finders of the triangulation system for positioning in the shortwave range. A method for estimating the coordinates of emitters by measuring the amplitudes of their signals by a system of softwarecontrolled receivers located in areas of electromagnetic accessibility is presented. Estimates of changes in the areas of location of objects in the joint assessment of the amplitudes of signals in the multi-position system of receivers-meters and directions of their arrival by remote direction finders.

Key words: direction finding, triangulation, radio wave propagation, Earth ionosphere, multiposition positioning system, orthodrome, azimuthю

\section{References}

1. Radyotekhnycheskaia razvedka / Yu. A. Smyrnov. - M. : Voenyzdat, $2006 . \quad-456$ s. 2. Dobrunyn Y.S. Optymyzatsyia razmeshchenyia sredstv radyokontrolia korotkovolnovoho dyapazona voln, yspolzuiushchykh pelenhatsyonnыi metod opredelenyia koordynat ystochnykov radyoyzluchenyia / Y.S. Dobrunyn, A.N. Bovkun, V.Y. Pysarevskyi // Zb. nauk. prats KhVU. - Kh. : KhVU, 2003. - № 3 (46). - S. 67-69. 3. Kotenko V.M., Melenskyi V.D., Shubin D.K.. Matematychna model zastosuvannia hradiientnykh metodiv dlia optymizatsii rozmishchennia zasobiv bahatopozytsiinoi radiopelenhatornoi merezhi korotkokhvylovoho diapazonu. Visnyk ZhDTU. Seriia "Tekhnichni nauky", 2014, 1(68), 59-65. (2014). 4. Dobrunyn Y.S. Optymyzatsyia razmeshchenyia sredstv radyokontrolia korotkovolnovoho dyapazona voln, yspolzuiushchykh pelenhatsyonnыi metod opredelenyia koordynat ystochnykov radyoyzluchenyia / Y.S. Dobronyn, A.N. Bovkun, V.Y. Pysarevskyi // Zb. nauk. prats KhVU. - Kh. : KhVU, 2003. - № 3 (46). - S. 67-69. 5. Kovbasiuk S.V. Metodyka optymizatsii struktury systemy radiomonitorynhu korotkokhvylovoho diapazonu khvyl / S.V. Kovbasiuk, O.I. Lohinov, V.P. Liubychenko // Zb. nauk. prats ZhVIRE. - Zhytomyr : ZhVIRE, 2004. 6. Slobodianiuk P.V. Radyomonytorynh: vchera, sehodnia, zavtra (Teoryia y praktyka postroenyia systemb radyomonytorynha) / P.V. Slobodianiuk, V.H. Blahodarnыi ; pod obshch. red. P.V. Slobodianiuka. - Pryluky : OOO «Yzdatelstvo «Air-Polihraf», 2010. - 296 s. 7. Kovbasiuk S.V. Metodyka optymyzatsyy vыbora parametrov strukturb mnohopozytsyonnoho radyolokatsyonnoho kompleksa / S.V. Kovbasiuk., A.A. Pysarchuk // Probl. upr. y ynformatyky. - 2003. - № 6. - S. 120-128. 8. Korotki khvyli: veb-sait. URL: https://ru.wikipedia.org/wiki/Korotkye volnы (data zvernennia 01.06.2021). 9. Kutomirni radionavihatsiini systemy: veb-sait. URL: https://studfile.net/preview/3642480/ (data zvernennia 17.09.2021). 10. Rembovskyi A.M., Ashykhmyn A.V., Kozmyn V.A. Radyomonytorynh: zadachy, metodu, sredstva (3 - e yzdanye, pod redaktsyei doktora tekh. nauk A.M. Rembovskoho, 2012 h. 640 s. 